\title{
Análise da produção de biogás sob diferentes cenários de gerenciamento de resíduos sólidos no município de Inconfidentes [MG]
}

\section{Letícia de Alcântara Moreira}

Mestrando em Meio Ambiente e Recursos Hidricos pela Universidade Federal de Itajubá. Graduada em Tecnologia em Gestão Ambiental. Itajubá [MG] Brasil <lemorera@hotmail.com>.

\section{Thaís Aparecida Costa da Silva}

Professora do Professora do Instituto Federal de Educação, Ciência e Tecnologia do Sul de Minas - Câmpus Inconfidentes. Inconfidentes [MG] Brasil <thaiscostaga@gmail.com>.

\section{Regina Mambeli Barros}

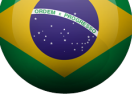

Professora Doutora da Universidade Federal de Itajubá. Itajubá [MG] Brasil <remambeli@hotmail.com>.

\section{Resumo}

A preocupação com os impactos negativos causados pela disposição inadequada dos resíduos sólidos tem crescido, principalmente no que se refere a sua influência sobre a atmosfera. 0 presente estudo teve como objetivo analisar a emissão de gases do efeito estufa sob diferentes cenários de gerenciamento de resíduos sólidos urbanos do município de Inconfidentes [MG], considerando os aspectos de crescimento populacional em um período de 30 anos, utilizando como ferramenta a planilha Warm. Após a análise dos dados obtidos foi possível constatar que a emissão de gases de efeito estufa são constantes, e são acrescidas com o aumento da geração de resíduos sólidos. Quanto aos cenários propostos observou-se que os mesmos não foram capazes de reduzir a emissão de gases, bem como tiveram o uso energético aumentado. Contudo, devem-se analisar outros fatores que estão associados ao manejo do cenário referência.

\section{Palavras-chave}

Manejo. Sustentabilidade. Disposição Final.

\section{Study of biogas production under different scenarios of solid waste management at Inconfidentes [state of Minas Gerais, Brazil]}

\begin{abstract}
The concern about negative impacts due to inappropriate solid waste disposal has been increased, mainly on atmosphere influence. This paper aims to analyze the emission of greenhouse gases under different scenarios of urban solid waste management at Inconfidentes city in the southeast region, assuming the population growth during 30 years and using Warm to run the analyses. After the data research, it was possible to noticed that the greenhouse gases emission are constant and improved by solid waste disposal. The different scenarios proposed were not able to reduce that emissio nor energetic use. However, other features should be considered under the reference scenario.
\end{abstract}

\section{Keywords}

Management. Sustainability. Final Disposition. 


\section{Introdução}

A geração de resíduos sólidos urbanos (RSU) é inerente a qualquer atividade antrópica, porém, é de suma importância que haja uma gestão integrada, de forma mitigar os impactos causados pela disposição inadequada dos mesmos. A Política Nacional de Resíduos Sólidos (PNRS) instituída pela Lei 12.305/2010 trouxe mudanças nos paradigmas da disposição final de RSU no Brasil, sendo importante ressaltar alguns princípios da referida lei, os quais: Responsabilidade compartilhada, análise do ciclo de vida, logística reversa, padrões sustentáveis de consumo e produção, reciclagem, integração dos catadores no gerenciamento, entre outros.

O ponto que mais chamou atenção na lei supracitada se dá com a meta de abolir os lixões até o final de 2014 (método de disposição final inadequado, o qual não se tem uma cobertura dos resíduos dispostos e nem impermeabilização do solo, trazendo inúmeros malefícios ambientais e sociais). Tal meta não foi cumprida e por meio de medida provisória aprovada no Congresso, o prazo para erradicação dos lixões no Brasil se estendeu para 2018.

A dificuldade dos municípios se adequarem a meta estabelecida pelo governo pode ser justificada por inúmeros motivos, dentre os quais se destaca principalmente a falta de recursos financeiros. Os municípios que são responsáveis pela gestão de resíduos sólidos urbanos, têm como desafio fornecer um sistema eficaz e eficiente aos seus habitantes, porém, muitas vezes enfrentam problemas além da capacidade municipal, tais problemas estão associados principalmente, à falta de organização, escassez recursos financeiros, e a complexidade do sistema multidimensional (Guerrero, Maas \& Hogland, 2013). Afinal a implantação e operação de um aterro sanitário demandam altos investimentos (método considerado ambientalmente adequado), lembrando que o Brasil possui em seu território muitos municípios considerados de pequeno porte (abaixo de 20.000 habitantes), uma solução que vem sendo adotada para o referido problema é a instituição de soluções consorciadas (Lei no 11.107 de 2005 e Art. 18 da Constituição Federal), assim como a terceirização dos serviços, onde há um investimento privado, o qual cobra pelo aterramento dos resíduos, geralmente o valor é cobrado por tonelada aterrada.

É de suma importância ressaltar que a PNRS não só estimula a disposição adequada dos resíduos sólidos, a qual deve ser feita em aterros sanitários, mas também tem como princípios anteriores a esse: a redução, reutilização e reciclagem.

Tendo em vista o contexto apresentado o presente trabalho tem por objetivo Analisar a emissão de gases do efeito estufa sob diferentes cenários de gerenciamento de resíduos sólidos urbanos do município de Inconfidentes [MG], considerando os aspectos de crescimento populacional em um período de 30 anos, utilizando como ferramenta a planilha Warm. Tais dados assumem relevância haja vista que o município ainda possui como método de disposição final de RSU, um lixão. Por fim, é de suma importância ressaltar a importância do aproveitamento energético dos resíduos sólidos urbanos. Landin e Azevedo (2008) na publicação intitulada "O aproveitamento energético do biogás em aterros sanitários: unindo o inútil ao sustentável" ressaltam a importância do aproveitamento do biogás gerado em aterros sanitários, como fonte de energia alternativa, trazendo benefícios ambientais, sociais e econômicos.

\section{Material e métodos}

\section{1. Área de estudo}

O município de Inconfidentes [MG], encontra-se localizado no sul do estado de Minas Gerais, possuía no ano de 2010 uma população de 6.908 habitantes com projeção para 2015 de 7290 habitantes (IBGE, 2010). 0 método utilizado para disposição final dos resíduos do município, é definido como lixão (Figura 1) conforme dados apresentados pela Fundação Estadual do Meio Ambiente de Minas Gerais e visita realizada ao local (FEAM, 2013).

Como pode ser observado na imagem o sistema possui vários agravantes ambientais. Silva e Liporone (2011) listaram as doenças que podem ser causadas pela disposição inadequada dos resíduos sólidos como o apresentado, onde os agentes biológicos fazem dos resíduos seu abrigo, sendo elas: 
Febre tifoide e ancilostomose (causada por moscas), amebíase (causada por moscas e baratas), poliomelite e gastroenterites (causada por baratas), elefantíase e febre amarela (causada por mosquitos), lepstopirose e peste (causada por ratos), toxoplasmose (causada por suínos e urubus) e hepatites infecciosa (causados por perfuro cortantes contaminados).

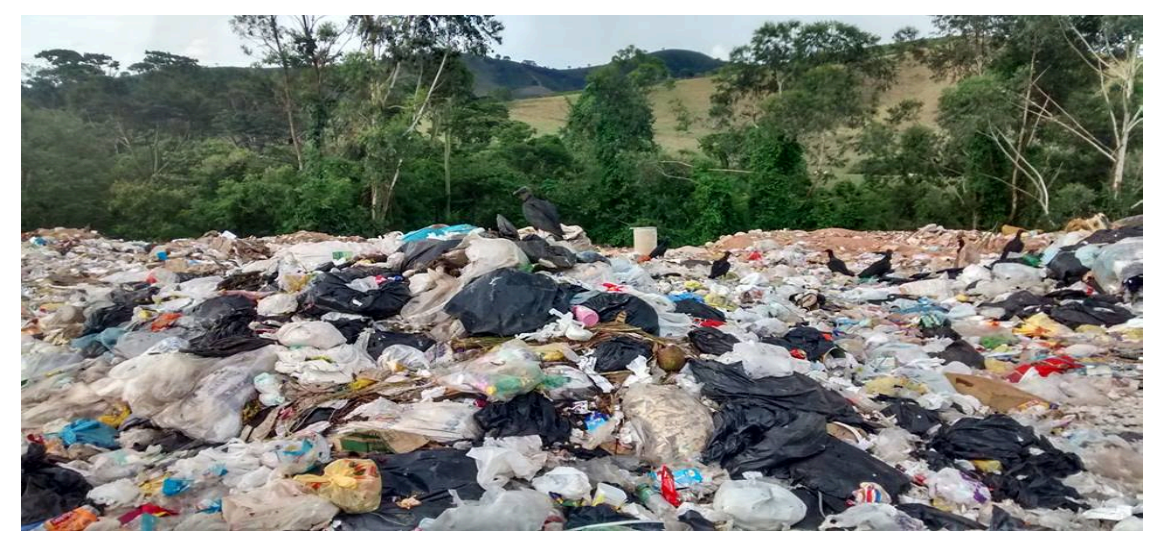

Figura 1. Sistema de disposição fina do Municipio de Inconfidentes. Foto: As próprias autoras, 2016.

\subsection{Projeção populacional}

Para a realização da análise do gerenciamento de resíduos sólidos faz-se necessário à adoção de técnicas que permitam realizar um planejamento de quais as possíveis características futuras do gerenciamento dos resíduos sólidos. Desta forma, adota-se análises de como a população poderá se comportar frente aos resíduos sólidos.

Neste estudo, através do Microsoft Excel foi realizada a projeção da população em um período de 30 anos, assim como recomendado por Dias Costa et al. (2016). Para a projeção da população foi realizada uma progressão aritmética.

Em função da projeção da população, foi calculada a quantidade de resíduos sólidos urbanos gerados ao longo de cada ano, considerando uma taxa de acréscimo na geração de resíduos sólidos de 1\% ao ano como no estudo de Dias Costa et al. (2016). Para tais cálculos, foram utilizados os dados de composição gravimétrica de Silva (2015) apresentado na Tabela 1, das de modo que pode-se obter qual a quantidade de resíduos sólidos acumulados ao longo de cada ano, permitindo desta forma observar o comportamento da geração de resíduos sólidos urbanos em um período de 20 a 30 anos a partir do ano de 2010.

Tabela 1. Composição gravimétrica do município de Inconfidentes [MG] no ano de 2015.

\begin{tabular}{l|c}
\hline Resíduos & Ton/Ano \\
\hline Vidro & 76,650 \\
\hline Papel/ papelão & 38.325 \\
Metal & 102,200 \\
\hline Plástico & 127,750 \\
\hline Matéria orgânica & 178,850 \\
\hline
\end{tabular}

Fonte: Adaptado de Silva, 2015.

\subsection{Cenários de gerenciamento de resíduos sólidos}

Para análise da geração dos gases de efeito estufa no município, foram adotados diferentes cenários, os quais apresentaram formas de manejo de resíduos sólidos que podem vir a ser adotadas. Os cenários são apresentados na Tabela 2. 
Tabela 2. Cenários de gerenciamento de resíduos sólidos para o município de Inconfidentes [MG].

\begin{tabular}{|c|c|c|c|c|}
\hline \multicolumn{5}{|c|}{ Cenário Referência } \\
\hline Resíduo & Compostagem & Reciclagem & $\begin{array}{l}\text { Aterramento } \\
\text { Aterro controlado }^{1}\end{array}$ & $\begin{array}{l}\text { Aterramento } \\
\text { Aterro sanitário }^{2}\end{array}$ \\
\hline Vidro & - & - & $100 \%$ & - \\
\hline Papel/papelão & - & - & $100 \%$ & - \\
\hline Metal & - & - & $100 \%$ & - \\
\hline Plástico & - & - & $100 \%$ & - \\
\hline Matéria orgânica & - & - & $100 \%$ & - \\
\hline \multicolumn{5}{|c|}{ Cenário 1 - Pouco Otimista } \\
\hline Vidro & - & - & - & $100 \%$ \\
\hline Papel/papelão & - & - & - & $100 \%$ \\
\hline Metal & - & - & - & $100 \%$ \\
\hline Plástico & - & - & - & $100 \%$ \\
\hline Matéria orgânica & - & - & - & $100 \%$ \\
\hline \multicolumn{5}{|c|}{ Cenário 2 - Muito Otimista } \\
\hline Vidro & - & $50 \%$ & - & $50 \%$ \\
\hline Papel/papelão & - & $50 \%$ & - & $50 \%$ \\
\hline Metal & - & $50 \%$ & - & $50 \%$ \\
\hline Plástico & - & $50 \%$ & - & $50 \%$ \\
\hline Matéria orgânica & $50 \%$ & - & - & $50 \%$ \\
\hline
\end{tabular}

${ }^{1}$ Refere-se ao aterro controlado localizado no município de Inconfidentes [MG].

${ }^{2}$ Refere-se ao aterro sanitário mais próximo da cidade, localizado no município de Pouso Alegre [MG].

Fonte: As próprias autoras, 2016.

\subsection{Análise da geração de Gases}

Para a determinação da emissão de gases do efeito estufa, os dados obtidos por meio da projeção da população, quantidade de RSU total e quantidade de SU referentes aos cenários foram inseridos na planilha Warm. Para tal foram adotados os valores referentes a transporte de 8 quilômetros quando disposto em aterro controlado, devido o município possuir este sistema de disposição e 60 quilômetros para aterro sanitário, uma vez que foi considerado o aterro sanitário particular mais próximo.

\section{Resultados e discussões}

Na Tabela 3 apresenta-se a projeção da população que se espera ter nos próximos anos, assim como a quantidade dos resíduos que a mesma irá gerar considerando os valores da composição gravimétrica.

Os dados descritos na Tabela 3 foram inseridos na Planilha Warm, considerando os aspectos de cada cenário. Sendo assim, obteve-se os valores apresentados na Tabela 4, onde tem-se as estimativas de geração de gases de efeito estufa sob diferentes manejo de resíduos sólidos no município de Inconfidentes [MG]. 
Tabela 3. Projeção populacional e volume de resíduos gerados no município de Inconfidentes [MG], a partir da composição gravimétrica de Silva (2015) calculada por meio do Microsoft Excel.

\begin{tabular}{|c|c|c|c|c|c|c|}
\hline Ano & População & Vidro & Papel & Metal & Plástico & Matéria Orgânica \\
\hline & Habitantes & \multicolumn{5}{|c|}{ Toneladas } \\
\hline 2016 & 7125 & 474,91265 & 237,45632 & 633,216866 & 791,521 & 1108,13 \\
\hline 2017 & 7161 & 558,220983 & 279,11049 & 744,294645 & 930,368 & 1302,52 \\
\hline 2018 & 7198 & 642,797149 & 321,39857 & 857,062865 & 1071,33 & 1499,86 \\
\hline 2019 & 7234 & 728,646304 & 364,32315 & 971,528405 & 1214,41 & 1700,17 \\
\hline 2020 & 7270 & 815,785451 & 407,89273 & 1087,71393 & 1359,64 & 1903,5 \\
\hline 2021 & 7306 & 904,231806 & 452,1159 & 1205,64241 & 1507,05 & 2109,87 \\
\hline 2022 & 7343 & 994,015024 & 497,00751 & 1325,35337 & 1656,69 & 2319,37 \\
\hline 2023 & 7379 & 1085,14065 & 542,57033 & 1446,8542 & 1808,57 & 2531,99 \\
\hline 2024 & 7415 & 1177,62655 & 588,81328 & 1570,16874 & 1962,71 & 2747,8 \\
\hline 2025 & 7451 & 1271,49083 & 635,74541 & 1695,32111 & 2119,15 & 2966,81 \\
\hline 2026 & 7487 & 1366,75179 & 683,3759 & 1822,33572 & 2277,92 & 3189,09 \\
\hline 2027 & 7524 & 1463,44084 & 731,72042 & 1951,25446 & 2439,07 & 3414,7 \\
\hline 2028 & 7560 & 1561,56404 & 780,78202 & 2082,08539 & 2602,61 & 3643,65 \\
\hline 2029 & 7596 & 1661,14039 & 830,5702 & 2214,85386 & 2768,57 & 3875,99 \\
\hline 2030 & 7632 & 1762,18915 & 881,09458 & 2349,58554 & 2936,98 & 4111,77 \\
\hline 2031 & 7668 & 1864,72981 & 932,36491 & 2486,30642 & 3107,88 & 4351,04 \\
\hline 2032 & 7705 & 1968,79561 & 984,39781 & 2625,06082 & 3281,33 & 4593,86 \\
\hline 2033 & 7741 & 2074,39316 & 1037,1966 & 2765,85754 & 3457,32 & 4840,25 \\
\hline 2034 & 7777 & 2181,54268 & 1090,7713 & 2908,72357 & 3635,9 & 5090,27 \\
\hline 2035 & 7813 & 2290,26465 & 1145,1323 & 3053,6862 & 3817,11 & 5343,95 \\
\hline 2036 & 7849 & 2400,57981 & 1200,2899 & 3200,77308 & 4000,97 & 5601,35 \\
\hline
\end{tabular}

Fonte: Adaptado de Silva, 2015.

No que se refere a Emissão de Gases de Efeito Estufa referentes à gestão de RSU, observa-se que quando não modificado o sistema de manejo de resíduos sólidos a taxa de emissão é constante, atingindo valores cada vez mais altos ao longo do tempo.

A mudança de manejo, de modo que os mesmos sejam encaminhados para um aterro sanitário ao invés de um aterro controlado é capaz de reduzir as emissões em primeiro momento, mas ao longo do tempo pode levar a uma maior emissão. Contudo, os resíduos quando dispostos em aterros sanitários, pode levar a um aproveitamento energético, ou queima dos gases, o que reduz os impactos sob a camada de ozônio.

Quanto ao manejo que opta por reciclagem, compostagem e aterro, nota-se que há um aumento na emissão de gases, contudo, estes valores não são drásticos, logo, deve-se considerar o fato de que estas opções de manejo podem auxiliar indiretamente na redução de impactos ambientais negativos, como redução de extração de matéria prima, utilização mais consciente de fertilizantes inorgânicos, entre outros benefícios. A mesma situação pode ser observada quando analisados em dados em MtCE. 
Tabela 4. Estimativa de geração de gases de efeito estufa sob diferentes manejo de resíduos sólidos no município de Inconfidentes [MG].

\begin{tabular}{|c|c|c|}
\hline \multicolumn{3}{|c|}{ Emissão de Gases de Efeito Estufa referentes à gestão de RSU (MtCO2) } \\
\hline & 2016 & 2036 \\
\hline Cenário Referência & 1242 & 6280 \\
\hline Cenário 1 & 1265 & 6.396 \\
\hline Cenário 2 & 1.282 & 6.480 \\
\hline \multicolumn{3}{|c|}{ Emissão de Gases de Efeito Estufa referentes à gestão de RSU (MtCE) } \\
\hline & 2016 & 2036 \\
\hline Cenário Referência & 339 & 1.713 \\
\hline Cenário 1 & 345 & 1.744 \\
\hline Cenário 2 & 350 & 1.767 \\
\hline \multicolumn{3}{|c|}{ Alterações total no uso energético (milhões de BTU): } \\
\hline & 2016 & 2036 \\
\hline Cenário Referência & 1243 & 6281 \\
\hline Cenário 1 & 1555 & 7.866 \\
\hline Cenário 2 & 1.781 & 9.002 \\
\hline
\end{tabular}

Fonte: As próprias autoras, 2016.

Quanto às alterações no uso energético, pode-se notar que nenhum cenário mostrou eficiência. Logo, faz-se necessário repensar em outras formas de manejo para os resíduos deste município. Augusto et al. (2016) realizou um estudo sobre manejo de resíduos sólidos em função de um projeto de consórcio para diferentes municípios e constatou que os cenários propostos por eles levaram a redução do uso energético, o que não corrobora com os dados desta pesquisa.

Dias Costa et al. (2016) através do Warm também analisou diferentes cenários de manejo de RSU para avaliar a proposta de um consórcio de aterro sanitário para os municípios de João Monlevade, Bela Vista de Minas, Rio Piracicaba e Nova Era em Minas Gerais. A pesquisa concluiu que a adoção de técnicas como o Warm e outras que analisam a emissão de GEE's são formas eficientes de analisar o potencial emissor de GEE e consequente potencial energético dos manejos propostos.

No trabalho de Silva et al. (2016) foi constatada a importância de uma gestão mais efetiva dos resíduos para emissão dos gases do efeito estufa, os autores realizaram simulações com o software WARM, para a cidade de Cruzeiro [SP], os resultados obtidos pelos autores também se diferem com os apresentados neste trabalho.

\section{Conclusão}

Após a análise dos dados obtidos por meio da planilha Warm, foi possível constatar que a emissão de gases de efeito estufa são constantes, e são acrescidas com o aumento da geração de resíduos sólidos.

Quantos aos cenários propostos, observou-se que os mesmos não foram capazes de reduzir a emissão de gases, bem como tiveram o uso energético aumentado. Contudo, deve-se analisar outros fatores que estão associados ao manejo do cenário referência, principalmente o fato de que o atual sistema de disposição trata-se de um lixão, o qual oferece inúmeros riscos aos recursos naturais, principalmente a água. 
São grandes os desafios para a gestão de RSU, mas é possível que novos cenários sejam criados e com isso a realidade brasileira seja mudada, é preciso um trabalho consistente de educação ambiental, para segregação dos resíduos e redução na fonte, porém é preciso ir além, é imprescindível o incentivo dos órgãos públicos, e investimento do mesmo em infraestrutura.

\section{Referências}

Augusto, M. et al. (2016). Gestão de Resíduos Sólidos do Consórcio Zona da Mata e Estimativa do Potencial de Aproveitamento Energético do Biogás na Região. Revista Brasileira de Energias Renováveis, pp.392-406 [Itajubá, MG].

Barros, R. M. (2013). Tratado sobre Resíduos Sólidos Gestão, Uso e Sustentabilidade. Rio de Janeiro: Interciência; Minas Gerais: Acta. 364 p. ISBN: 9788571932951.

Brasil (1988). Constituição da Republica Federativa do Brasil de 5 de Outubro de 1988 (Artigo no18). Recuperado de: http://www.planalto.gov.br/ccivil_03/constituicao/constituicaocompilado.htm>

Brasil (2005). Lei Federal no11.107 de 6 de Abril de 2005. Dispõe sobre normas gerais de contratação de consórcios públicos e dá outras providências. Recuperado de: < http://www.planalto.gov.br/ccivil_03/ _ato2004-2006/2005/Lei/L11107.htm>

Brasil (2010). Lei Federal nº12. 305 de 2 de Agosto de 2010. Institui a Política Nacional de Resíduos Sólidos; altera a Lei no 9.605, de 12 de fevereiro de 1998 e dá outras providências. Recuperado de: <http:// www.planalto.gov.br/ccivil_03/_ato2007-2010/2010/lei/112305.htm>

Dias Costa, A. M. et al. (2016). Dimensionamento de Diferentes Cenários na Destinação de Resíduos Sólidos no Aterro Sanitário - CPGRS. Revista Brasileira de Energias Renováveis, 5 (3), 343-355.

Fundação Estadual de Meio Ambiente (2013). Inventário sobre a destinação final de resíduos sólidos (2013): Minas sem Lixões. Recuperado de: http://www.feam.br/images/stories/minas_sem_lixoes/2013/novo/ rsu_2012_final_300dpi.pdf.>

Guerrero, L. A., Maas, G., \& Hogland, W. (2013). Solid waste management challenges for cities in developing countries. Waste Management, [s.l.], 33 (1) 220-232. Recuperado de: <http://dx.doi.org/10.1016/ j.wasman.2012.09.008>.

IBGE (2010). Minas Gerais — Inconfidentes: Informaç̧oes completas. Recuperado de: http://cod.ibge.gov.br/ $\mathrm{G} 2 \mathrm{H}$

Landim, A. L. P. F., \& Azevedo, L. P. de. (2008). O aproveitamento energético do biogás em aterros sanitários: unindo o inútil ao sustentável. (27ạ. ed) Rio de Janeiro: Bndes Setorial.. (42p.) . Recuperado de: <http:// www.bndes.gov.br/SiteBNDES/bndes/bndes_pt/Galerias/Convivencia/Publicacoes/Consulta_Expressa/ Setor/Meio_Ambiente/200803_2.html.>.

SILVA, É. L. A. (2015). Estudo prévio da viabilidade econômica da implantação da coleta seletiva e unidade de triagem em Inconfidentes-MG. TCC (Graduação) Curso de Gestão Ambiental, IFSULDEMINAS-Câmpus Inconfidentes, Inconfidentes, MG, Brasil.

Silva, L. O. et al. (2016) Análise de viabilidade do aproveitamento energético do gás de aterro para a cidade de Cruzeiro [SP]. Labor \& Engenho 10 (1), 07-16. Recuperado de: http://dx.doi.org/10.20396/ lobore.v10i1.8641867.

Silva, C. B. da \& Liporone, F. (2011) Deposição irregular de resíduos sólidos domésticos em Uberlândia: Algumas considerações. Observatorium: Revista Eletrônica de Geografia, 2 (6) 22-35 [Uberlândia, MG]. Recuperado de: $<$ http://www.observatorium.ig.ufu.br/pdfs/2edicao/n6/3.pdf.>. Acesso em: 01 dez. 2016. 